\title{
The Relationship between The Promotion of Library Service and Increased Student Visits to School Library
}

\section{Hubungan Promosi Layanan Perpustakaan Dalam Meningkatkan Kunjungan Siswa Pada Perpustakaan Sekolah}

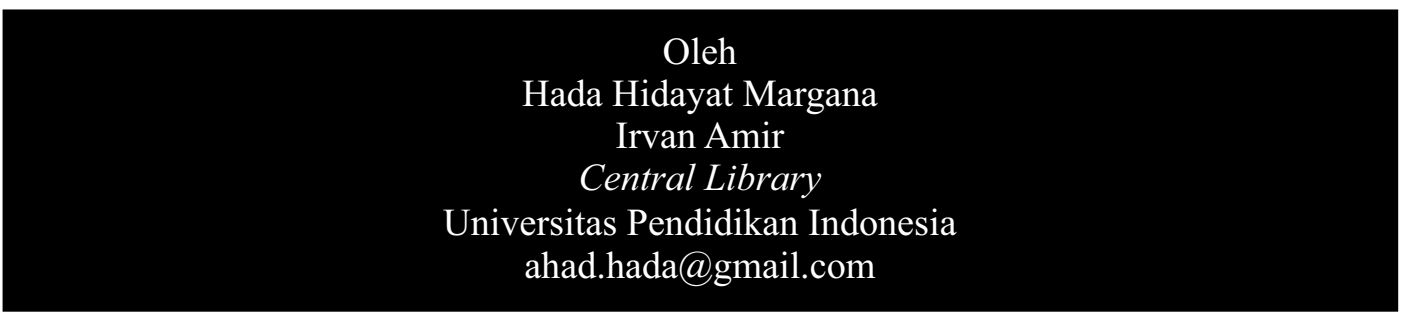

Abstract. This research is a descriptive study that aims to describe the relationship promotion of library services in improving student visits. Promotion of library services is one of the programs of work done by librarians in attracting the visitors to come to the library. This research was conducted at the National High School Library 6 Bandung, which is located at Pasirkaliki Street No. 51 Bandung. This study used a descriptive method with a quantitative approach. Sample study amounted to 87 people who were determined by the formula Yamane and sampling technique used is simple random sampling. In general, the results showed that the relationship promotion of services in a very significant increase student visits. Meanwhile, in particular, the results showed that (1) Performance in promoting library librarians are very influential in improving student visits

to the library. (2) Means promotion effect in improving students' visits to the library. It can be concluded that the promotion of library services can increase student visits to the library.

Keyword : Promotion of Library Services, School Library, Student Visits.

Abstrak. Penelitian ini merupakan penelitian deskriptif yang bertujuan untuk menggambarkan hubungan promosi layanan perpustakaan dalam meningkatkan kunjungan siswa. Promosi layanan perpustakaan merupakan salah satu program kerja yang dilakukan oleh pustakawan dalam memikat pemustaka untuk datang ke perpustakaan. Penelitian ini dilakukan di Perpustakaan Sekolah Menengah Atas Negeri 6 Bandung, yang berlokasi di Jalan Pasirkaliki No. 51 Bandung. Penelitian ini menggunakan metode deskriptif dengan pendekatan kuantitatif. Sample penelitian berjumlah 87 orang yang ditentukan dengan rumus yamane dan teknik sampling yang digunakan adalah simple random sampling. Secara umum, hasil penelitian menunjukkan bahwa hubungan promosi layanan dalam meningkatkan kunjungan siswa sangat signifikan. Sedangkan secara khusus, hasil penelitian menunjukkan bahwa (1) Kinerja pustakawan dalam mempromosikan perpustakaan meningkatkan kunjungan siswa ke perpustakaan. (2) Sarana promosi meningkatkan kunjungan siswa ke perpustakaan. Dengan demikian dapat disimpulkan bahwa promosi layanan perpustakaan dapat meningkatkan kunjungan siswa ke perpustakaan.

Kata Kunci: Promosi Layanan Perpustakaan, Perpustakaan Sekolah, Kunjungan Siswa. 


\section{PENDAHULUAN}

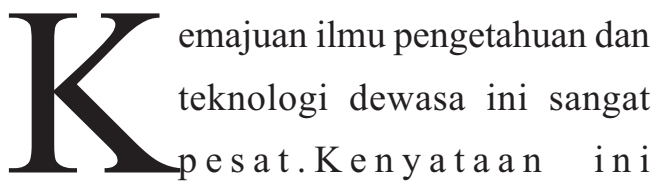

mempengaruhi tuntuatan masyarakat terhadap dunia pendidikan pada umumnya baik secara kuantitas maupun kualitas. Sebagai dampak lain dari hal tersebut, lembaga pendidikan harus mampu mengikuti dan sekaligus menyelaraskan diri dengan tuntutan dan kebutuhan masyarakat.

Sekolah yang merupakan salah satu lembaga pendidikan mempunyai peran yang cukup penting dalam membangun generasi yang lebih baik. Dalam penyelenggaraannya, sekolah yang berkualitas harus di dukung oleh sarana dan prasarana yang memadai guna menunjang kegiatan pembelajaran di lingkungan sekolah tersebut. Salah satu sarana penunjang utama kegiatan pembelajaran di sekolah adalah perpustakaan. Sulistyo-Basuki (1993, hlm. 50) menyebutkan bahwa: "Perpustakaan sekolah adalah perpustakaan yang tergabung pada sebuah sekolah, dikelola sepenuhnya oleh sekolah yang bersangkutan, dengan tujuan utama membantu sekolah untuk mencapai tujuan khusus sekolah dan tujuan pendidikan pada umumnya". Dari definisi tersebut dapat disimpulkan bahwa perpustakaan adalah sarana dan fasilitas yang disediakan oleh sekolah dalam mengelola bahan bacaan untuk dimanfaatkan oleh masyarakat yang berada dilingkungan sekolah tersebut guna mencapai tujuan khusus sekolah dan tujuan pendidikan pada umumnya.
Segala kebutuhan informasi yang diperlukan oleh guru maupun siswa terdapat di perpustakaan. Tidaklah heran mengapa perpustakaan disebut sebagai jantung pendidikan, karena perpustakaan menyimpan dan mengolah informasi yang nantinya akan dibutuhkan oleh siswa maupun guru dalam kegiatan pembelajaran.

Dalam kenyataannya pemanfataan perpustakaan sekolah oleh masyarakat sekolah masih jauh dari yang diaharapkan. Salah satu cara dalam menarik perhatian siswa untuk membujuk mereka datang ke perpustakaan adalah dengan melakukan promosi perpustakaan. Hal ini dilakukan agar siswa dapat mengetahui layanan dan koleksi yang ada di perpustakaan. Tidak hanya itu promosi perpustakaan juga dimaksudkan untuk memberi motivasi kepada siswa akan pentingnya memanfaatkan perpustakaan. Menurut Sihabbudin (2003) tujuan promosi perpustakaan adalah :

1.) Memperkenalkan fungsi perpustakaan kepada masyarakat pemakai

2.) Mendorong minat baca dan mendorong masyarakat agar menggunakan koleksi perpustakaan semaksimalnya dan menambah jumlah orang yang membaca

3.) Memperkenalkan pelayanan dan jasa perpustakaan kepada masyarakat.

Berdasarkan penjabaran di atas mengenai tujuan promosi layanan perpustakaan dapat ditarik kesimpulan bahwa untuk 
meningkatkan pemanfaatan perpustakaan, kemampuan perpustakaan seyogyanya harus diketahui oleh siswa,serta produk dan layananpun harus dimanfaatkan dengan baik, sehingga tingkat kujungan ke perpustakaan akan semakin tumbuh dan meningkat.

Pelaksanaan promosi perpustakaan tidak hanya dilakukan oleh pustakawan itu sendiri, tetapi seluruh elemen yang berada di lingkungan sekolah tersebut, mulai dari guru mata pelajaran, guru Bimbingan Konseling, dan juga kepala sekolah. Dengan promosi perpustakaan yang baik maka siswa akan lebih memanfaatkan perpustakaan sebagai tempat pemenuhan kebutuhan informasinya dan tingkat kunjungan siswa ke perpustakaanpun akan lebih meningkat.

Promosi seyogianya mempunyai dampak yang berkesinambungan dan menghasilkan kemajuan, yang artinya harus ada peningkatan pendayagunaan perpustakaan oleh pemustaka. Menurut Mustafa (2009, hlm. 21)“.....dengan adanya promosi perpustakaan dapat mempengaruhi faktor sosial psikologis pemustaka, yaitu:

1.) Meningkatkan kebiasaan menggunakan perpustakaan.

2.) Menunjukan baga imana perpustakaan dapat memenuhi kebutuhan individu pemustaka.

3.) Berusaha mengubah pola pikir dan pola tindak pengguna dalam hal pemustaka dalam hal pengguanaan perpustakaan, walaupun pekerjaan ini sangat berat tetapi sesungguhnya merupakan salah satu tugas dan tanggung jawab pustakawan."

Dari pemaparan tersebut maka dapat diartikan bahwa pelaksanaan promosi layanan di perpustakaan, dapat dijadikan sebagai alat dalam meningkatkan tingkat kunjungan siswa ke perpustakaan. Karena dengan adanya promosi layanan perpustakaan, diharapkan siswa dapat mengetahui layanan dan koleksi yang dimiliki oleh perpustakaan.

Metode yang digunakan dalam penelitian ini adalah menggunakan metode deskriptif dengan pedekatan kuantitatif. Populasi yang menjadi ruang lingkup penelitian adalah siswa kelas XI dan kelas XII, dengan teknik pengambilan sampel menggunakan teknik simple random sampling.

Berdasarkan perhitungan sampel dengan menggunakan rumus taro yamane, maka diperoleh jumlah responden sebesar 87 orang dari seluruh siswa kelas XI dan kelas XII. Berikut ini merupakan tahapan-tahapan dalam penulisan karya ilmiah:

1.) Pemilihan dan identifikasi masalah

2.) Penentuan sampel penelitian

3.) Menentukan instrumen

4.) Prosedur dan desain penelitian

5.) Pengumpulan data

6.) Analisis dan interpretasi data

7.) Penyususnan laporan secara ilmiah

Untuk mempermudah penulis, maka analisis dan pengolahan data menggunakan aplikasi SPSS 16.0. 


\section{HASIL DAN PEMBAHASAN}

Pembahasan mengenai hubungan promosi layanan dengan tingkat kunjungan siswa berdasarkan hasil pengujian hipotesis melalui uji korelasi yang dilakukan menunjukan bahwa, terdapat hubungan yang signifikan antara promosi layanan perpustakaan dengan indikator advertising, sales promotion, public relation, personal selling dan direct marketing dan dengan tingkat kunjungan dengan indikator daya tarik sosial, daya tarik prestise, daya tarik pertahanan hidup, daya tarik kesenangan, daya tarik egomaniak, dan daya tarik menakuti, maka diperoleh nilai sebesar sebesar $\pm 0,899$ yang berarti apabila ditafsirkan berdasarkan kriteria penafsiran nilai korelasi, maka tingkat korelasi kedua variabel berarti pada tingkat hubungan sangat kuat, pada rentang 0,80-1,000. Dengan demikian dapat dikatakan bahwa hasil pengujian hipotesis yang dilakukan menunjukan $\mathrm{H} 0$ ditolak dan $\mathrm{H} 1$ diterima.

\section{KESIMPULAN}

Berdasarkan hasil penelitian yang telah dilaksanakan, kenyataan di lapangan menunjukkan terdapat hubungan yang positif dan signifikan antara promosi layanan perpustakaan dengan kunjungan siswa. Hasil penelitian dan hasil analisis data, diperoleh nilai koefisien korelasi sebesar $\pm 0,899$. Hal ini menunjukan bahwa promosi layanan perpustakaan dapat meningkatkan kunjungan siswa ke perpustakaan. Gambaran kinerja pustakawan dan sarana promosi mempunyai hubungan yang sangat kuat dalam meningkatkan kunjungan siswa ke perpustakaan.

Saran yang dapat diberikan oleh peneliti kepada perpustakaan SMA Negeri 6 Bandung adalah program promosi perpustakaan sekolah lebih diintensifkan lagi, agar siswa lebih mengetahui fasilitas dan layanan yang tersedia di perpustakaan serta perlunya pendekatan personal kepada setiap siswa, agar lebih termotivasi untuk dapat memanfaatkan perpustakaan.

\section{DAFTAR PUSTAKA}

Achmad, dkk.. (2012). Layanan Cinta: Perwujudan Layanan Prima Perpustakaan. Jakarta: Sagung Seto.

Arikunto, Suharsimi. (2010). Prosedur Penelitian: Pendekatan Praktik. Jakarta: Rineka Cipta.

Bafadal, Ibrahim. (2009). Pengelolaan Perpustakaan Sekolah. Jakarta: Bumi Aksara.

HS, Lasa. (2007). Manajemen Perpustakaan Sekolah. Yogyakarta: Pinus.

Hurriyati, Ratih. (2010). Bauran Pemasaran dan Loyalitas Konsumen. Bandung: Alfabeta.

Kamus Besar Bahasa Indonesia. (2008). Jakarta: Balai Pustaka.

Komaruddin dan YookeTjuparmah S. Komaruddin. (2002). Kamus Istilah Karya Tulis Ilmiah. Jakarta: BumiAksara.

Kotler, Philip dan Gary Amstrong. (2008). Prinsip-Prinsip Pemasaran, Ed. 12, Jil. 2. Jakarta: Erlangga. 
Machfoedz, Mahmud. (2010). Komunikasi Pemasaran Modern. Yogyakarta: Cakra Ilmu.

Mustafa, Badollahi. (2009). Promosi Jasa Perpustakaan. Jakarta: Universitas Terbuka.

Rangkuti, Freddy. (2002). Creating Effective Marketing Plan: Teknik Membuat Rencana Pemasaran Berdasarkan Customer Values \& Analisis Kasus. Jakarta: Gramedia PustakaUtama.

Saleh, Abdurahman. (2009). Manajemen Perpustakaan. Jakarta: Universitas Terbuka.

Sinaga, Dian. (2009). Mengelola Perpustakaan Sekolah. Bandung: Bejana.

Sugiyono. (2012). Metode Penelitian Pendidikan: Pendekatan Kualitatif, Kuantitatif, dan R\&D. Bandung: Alfabeta.

Sulistyo-Basuki, (1993). Pengantar Ilmu Perpustakaan. Jakarta: Gramedia Pustaka Utama.

Peraturan Menteri Pendidikan Nasional Nomor 25 Tahun 2008 Tentang Kompetensi Pustakawan.

Rahayuningsih. (2007). Pengelolaan Perpustakaan. Yogyakarta: Grahallmu.

Yusuf, Pawit M. (2007). Pedoman Penyelenggaraan Perpustakaan Perpustakaan Sekolah. Jakarta: Kencana. 